\section{Control of Methicillin-Resistant Staphylococcus aureus in a Tertiary Hospital with Low Background Endemicity: Evidence That Interventions Do Work}

TO THE EDITOR-It is well recognized that controlling the spread of methicillin-resistant Staphylococcus aureus (MRSA) in healthcare settings is important. MRSA is a major cause of hospital-acquired infection, and is associated with significant morbidity and mortality. While it may be debated whether measures such as the isolation of patients colonized or infected with MRSA are supported by sufficient scientific rigor, there is little doubt that good infection control practices, such as adherence to hand hygiene and barrier techniques, are warranted. ${ }^{1,2}$

Auckland City Hospital (ACH) is a 900-bed tertiary care teaching hospital that serves a population of 450,000 people; it has approximately 73,000 admissions annually. MRSA was first isolated in New Zealand in $1975,{ }^{3}$ but only emerged as a problem in hospitals throughout the country following the introduction of the endemic UK strain, E-MRSA 15, in the late 1990s. This strain became established in ACH despite attempts to control its spread. By 2000, the incidence of new MRSA isolates among ACH patients was approximately 6 isolates per 1,000 patients admitted. From 2000-2002, episodes of cross-transmission occurred in vascular and general surgery and in the older persons' health service, corresponding to an increased overall incidence of approximately 8.0 cases per 1,000 patients admitted, Figure 1 .

In response to this, several changes were made to the hospital's MRSA policy. First, the previous policy had been to perform targeted MRSA surveillance if a patient was admitted from an overseas hospital or from a New Zealand hospital with a documented case of cross-transmission in the preceding 6 months; this surveillance policy was extended to cover patients admitted from residential care facilities. This decision was based on a study in 2001 that found $9 \%$ of patients admitted to $\mathrm{ACH}$ from a residential care facility were colonized or infected with MRSA, compared with $3 \%$ of similarly aged patients from the community. ${ }^{4}$

Second, alcohol-based hand gel was introduced to all clinical care areas in 2002. Intensive education about its use was given to all healthcare worker (HCW) groups, which is reinforced annually with a week-long educational campaign. This remains an area for ongoing improvement at $\mathrm{ACH}$, as an audit of medical staff hand hygiene adherence on ward rounds demonstrated compliance of only $60 \%{ }^{5}$

Third, in November 2003 the hospital moved to a new facility. In contrast to the previous facility, the new facility had more single rooms with private bathrooms, as well as more rooms with 4 beds rather than 6 . Hand-washing stations were placed inside the room near the door, so that they were easily visible to HCWs as they entered and exited. Handwashing stations were also located in alcoves throughout ward corridors, and alcohol-based hand gel dispensers were placed immediately outside of all rooms. In high-risk areas, such as intensive care units, hand gel dispensers were also attached to the nursing trolley beside each patient.

It is not our routine practice to decolonize patients who are colonized with MRSA, because there is a moderately high rate of mupirocin resistance among $S$. aureus isolates in New Zealand ${ }^{6}$ and there is a lack of evidence for persistent clearance among patients with MRSA colonization at more than 1 site. $^{7}$ Until recently, HCWs have been screened for MRSA colonizatiōn prior to commencing employment, and those found to be colonized were decolonized before starting work in a clinical care area. From April 2004 to April 2007, only $55(1.3 \%)$ of 4,280 newly employed HCWs were found to be colonized with MRSA; this low number, as well as the lack of supporting evidence for the benefit of decolonization, led us to discontinue this practice.

For the past 20 years, $\mathrm{ACH}$ has had a strong focus on good antibiotic stewardship. The prescription of vancomycin, broad-spectrum $\beta$-lactams, and/or quinolone antibiotics requires permission from an infectious diseases physician or microbiologist. Emphasis is also placed on prescribing narrow-spectrum antibiotics once the infecting organism and its antibiotic susceptibilities are known.

The average monthly incidence of new cases of MRSA colonization at ACH peaked in mid-2002 at 8.0 cases per 1,000 patients admitted, and since then we have seen a significant decline to 2.7 cases per 1,000 patients admitted in

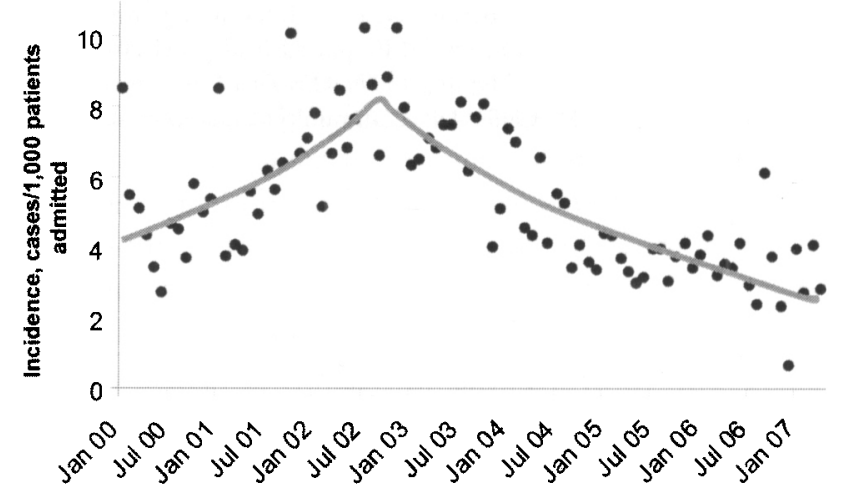

FIGURE. Incidence of new cases of methicillin-resistant Staphylococcus aureus colonization or infection in the study hospital from January 2000 to April 2007. Each dot represents the value for 1 month; the curve shows the mean value. $P=.001$ for the peak in 2002 vs the trough in 2007 . 
April 2007 ( $P=.001)$ (Figure). We attribute this decline to the implementation of targeted active surveillance, the introduction of alcohol-based hand gels, rigorous antibiotic stewardship, and the introduction of improved hand hygiene facilities in the new hospital. This decrease in the incidence of MRSA infection and/or colonization at $\mathrm{ACH}$ has occurred despite an increase in the annual incidence rate nationally and regionally; the incidence for the Auckland region exceeds 200 cases per 100,000 population. ${ }^{8}$

Worldwide, policies for hospital MRSA management range from "search and destroy" in The Netherlands (where an extremely low prevalence of MRSA infection is enjoyed) ${ }^{9}$ to less stringent approaches that are often associated with a sense that the problem can no longer be controlled. ${ }^{10}$ We present evidence that a significant reduction in the incidence of MRSA infection and/or colonization can be achieved by the expansion of targeted MRSA surveillance to include high-risk groups, combined with improvement of facilities to provide good access to hand hygiene equipment and alcohol-based hand gel along with a background of conservative antibiotic stewardship and ongoing emphasis on excellence in our infection control practice.

\section{ACKNOWLEDGMENTS}

We acknowledge the hard work of other members of the Auckland City Hospital infection control team, including Deborah Jowitt and Arthur J. Morris.

Potential conflicts of interest. All authors report no conflicts of interest relevant to this article.

Arlo Upton, MBChB; Camilla McGuiness, BHSc;
From Clinical Microbiology, LabPlus (A.U., S.A.R.) and Infection Control (C.M.), Auckland City Hospital, and the Children's Research Centre, Starship Hospital (P.R.), Auckland, New Zealand.

Address reprint requests to Arlo Upton, MBChB, LabPlus, Auckland City Hospital, PO Box 110031, Auckland, New Zealand (arlou@adhb.govt.nz). Infect Control Hosp Epidemiol 2007; 28:1318-1319

(C) 2007 by The Society for Healthcare Epidemiology of America. All rights reserved. 0899-823X/2007/2811-0018\$15.00. DOI: $10.1086 / 522677$

\section{REFEREN CES}

1. Cooper BS, Stone SP, Kibbler CC, et al. Isolation measures in the hospital management of methicillin-resistant Staphylococcus aureus (MRSA): systematic review of the literature. $B M J$ 2004; 329:533.

2. Duckworth G. Controlling methicillin-resistant Staphylococcus aureus. BMJ 2003; 327:1177-1178.

3. Humble MW. Imported methicillin-resistant Staphylococcus aureus infection: a case report. $N Z$ Med J 1976; 84:476-478.

4. Briggs $S$, McGuiness $C$, Foster M, et al. A reservoir for methicillinresistant Staphylococcus aureus in the Auckland community? N Z Med J 2002; 115:U182.

5. Roberts S, Upton A, Morris A, et al. Hand-hygiene practices of medical staff: room for improvement. $N Z$ Med J 2005; 118:U1311.

6. Upton A, Lang S, Heffernan H. Mupirocin and Staphylococcus aureus: a recent paradigm of emerging antibiotic resistance. J Antimicrob Chemother 2003; 51: 613-617.

7. Harbarth S, Liassine N, Dharan S, et al. Risk factors for persistent carriage of methicillin-resistant Staphylococcus aureus. Clin Infect Dis 2000; 31: 1380-1385.

8. Heffernan H. Annual survey of methicillin-resistant Staphylococcus aureus (MRSA), 2006. NZ Public Health Report 2007; 5:4-5. Available at: http://www.surv.esr.cri.nz/PDF_surveillance/Antimicrobial/aMRSA_ 2006.pdf. Accessed September 24, 2007.

9. Wertheim HF, Vos MC, Boelens HA, et al. Low prevalence of methicillinresistant Staphylococcus aureus (MRSA) at hospital admission in The Netherlands: the value of search and destroy and restrictive antibiotic use. $J$ Hosp Infect 2004; 56:321-325.

10. Boyce JM, Cookson B, Christiansen K, et al. Methicillin-resistant Staphylococcus aureus. Lancet Infect Dis 2005; 5:653-663. 